\title{
Fnac of Rosai - Dorfman Disease - Report of 5 Cases
}

\author{
Neeraj Dhameja ${ }^{1}$, Deepshikha ${ }^{1 *}$, Shreekant Bharti ${ }^{1}$ and Chakrapani Awasthi ${ }^{2}$ \\ 'Department of Pathology , Institute of medical sciences, Banaras Hindu University, Varanasi, U.P, India \\ ${ }^{2}$ Department of Radiotherapy, King George Medical University, Lucknow, U.P, India
}

\begin{abstract}
Sinus histiocytosis with massive lymphadenopathy (SHML) is a rare non malignant histiocytic proliferative disorder of unknown etiology presenting with massive lymphadenopathy. These cases can often be misdiagnosed as lymphoma. Very few cases has been diagnosed on FNAC. Here we report 5 cases of Rosai - Dorfman disease presenting with massive bilateral cervical lymphadenopathy. Hence FNAC is a useful and reliable tool for the diagnosis of Rosai-Dorfman disease due to which biopsy can be avoided in these patients 0
\end{abstract}

Keywords: Rosai-Dorfman disease, Lymphadenopathy, FNAC, Giemsa stain, Papanicolaou stain

\section{Introduction}

FNAC are commonly done for any palpable lymph node and most important clinical diagnosis is either infective or neoplastic pathology. Rarely it may show unusual findings. Rosai - Dorfman Disease is a rare benign self limiting disorder that commonly involve lymph nodes. It is also referred to as sinus histiocytosis with massive lymphadenopathy (SHML). Mostly children and young adult in the second decade are affected with a slight male preponderance. ${ }^{[1,2]}$ It mainly present as massive bilateral painless cervical lymphadenopathy. Extra nodal disease is also common, often with a particular predilection for head and neck region. ${ }^{[3]}$ Only few cases of Rosai - Dorfman Disease have been reported on FNAC. Here we describe 5 cases of lymph nodes FNAC showing features of Rosai - Dorfman disease.

\section{Case Reports}

Total 5 cases were included in the study of which 4 were males and 1 was female. The study included 2 paediatric

Tables:

\begin{tabular}{|c|c|c|c|}
\hline Cases & Age and sex & Clinical features & Diagnosis \\
\hline Case no 1 & $11 \mathrm{Y} / \mathrm{M}$ & Enlarged left cervical lymph node & $\begin{array}{l}\text { Rosai - Dorfman Disease -on FNAC } \\
\text { Histopathology }\end{array}$ \\
\hline Case no 2 & $7 \mathrm{Y} / \mathrm{M}$ & Bilateral enlarged cervical lymph node & Rosai - Dorfman Disease - on FNAC \\
\hline Case no 3 & $18 \mathrm{Y} / \mathrm{F}$ & $\begin{array}{l}\text { Bilateral multiple enlarged cervical lymph node ranging } \\
\text { from } 1^{*} 1 \mathrm{~cm} \text { to } 5^{*} 4 \mathrm{~cm} \text { since } 2 \text { year. History of on and off } \\
\text { fever was present since } 1 \text { year }\end{array}$ & Rosai - Dorfman Disease - on FNAC \\
\hline Case no 4 & $18 \mathrm{Y} / \mathrm{M}$ & $\begin{array}{l}\text { Bilateral enlarged cervical lymph node measuring from } \\
2^{*} 2 \mathrm{~cm} \text { to } 3^{*} 3 \mathrm{~cm} \text { since } 2 \text { year, history of weight loss was } \\
\text { also present since one year, History of on and off fever } \\
\text { was present. }\end{array}$ & Rosai - Dorfman Disease - on FNAC \\
\hline Case no 5 & 29Y/M & $\begin{array}{l}\text { Enlarged right cervical lymphnode measuring } 5 * 4 \mathrm{~cm} \mathrm{~cm} \\
\text { since } 3-4 \text { months. History of on and off fever was present }\end{array}$ & Rosai - Dorfman Disease - on FNAC \\
\hline
\end{tabular}

patients (one was $11 \mathrm{yr}$ old and another was $7 \mathrm{yr}$ old) and 3 adult patients( 2 patients of $18 \mathrm{yrs}$ age and one of $29 \mathrm{yrs}$ age). All patients presented with enlarged cervical lymph grade fever was present in 3 cases. No other significant history of weight loss or cough was present. FNAC was advised with a clinical impression of tuberculosis or lymphoma. FNAC was done in the department of Pathology IMS, BHU with $23 \mathrm{G}$ needle. Both air dried and alcohol fixed smears were made and Giemsa and Papanicolaou stain was done. All cases showed similar morphology with presence of histiocytes showing emperipolesis of lymphocytes and plasma cells on a background of reactive population of lymphoid cells(Fig1A-3B). No granuloma, parasite, Reed- Sternberg cells, or atypical lymphoid cells seen. Based on these morphological features, a diagnosis of Rosai - Dorfman Disease was made. Histopathological examination was done in one case (case 1) which confirmed the cytological diagnosis of Rosai-Dorfman Disease nodes ranging from 1 to $4 \mathrm{~cm}$ in diameter. History of low 


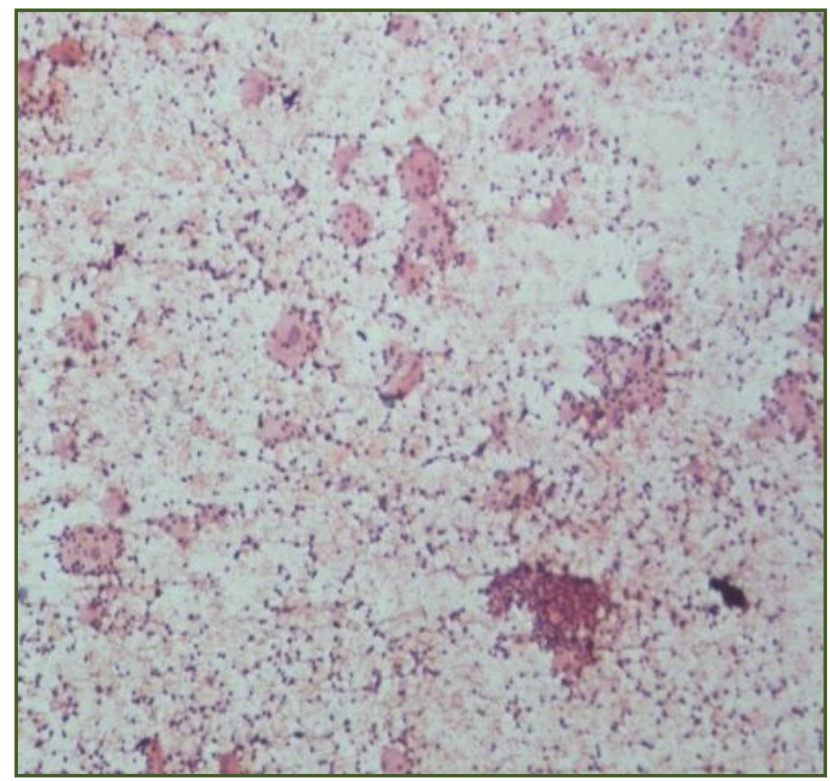

Fig. 1A: 10 X Papanicolaou showing emperipolesis.

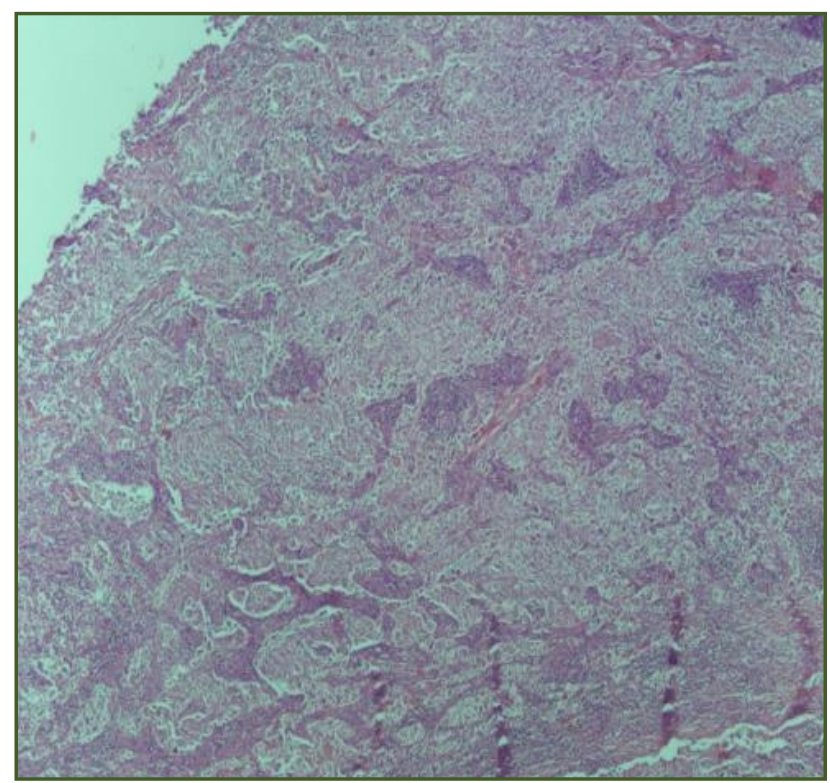

Fig. 2: 4 X H \& E showing effaced nodal architecture.

\section{Discussion}

FNAC is commonly done for enlarged lymph nodes. The diagnostic sensitivity of FNAC of lymph node is usually above $95 \%$ and specificity is also very high. It may be unguided for external lymph nodes and guided for internal lymph nodes . Most important differential diagnosis is Tuberculosis versus Malignancy (lymphoma/metastasis). Rarely lymph nodes may show unexpected morphology such as Rosai-Dorfman Disease. Most cases of Rosai Dorfman Disease occur during the first or second decade of life. However any age group may be affected with slight

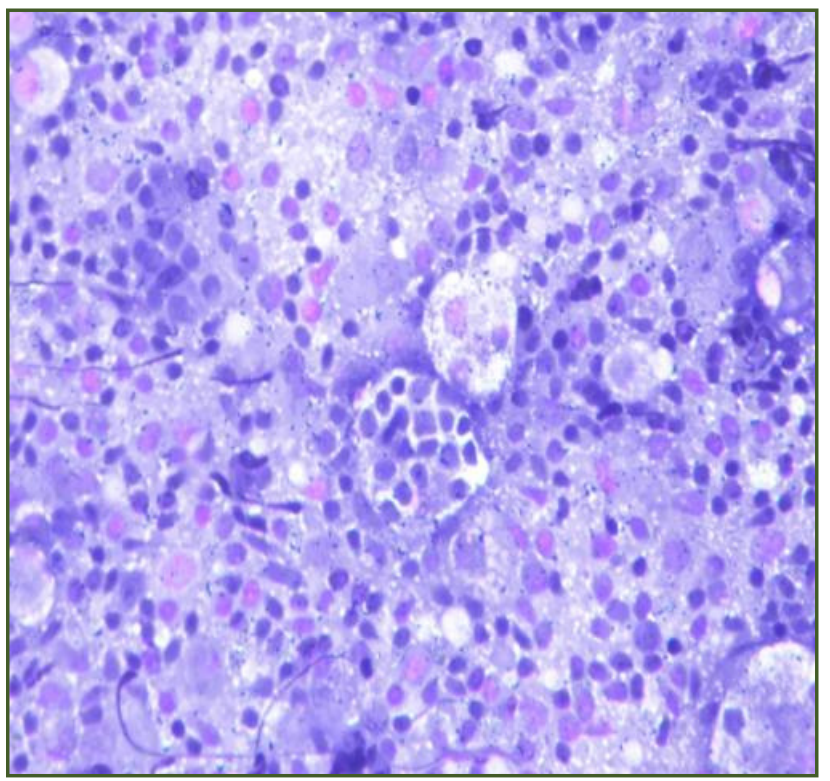

Fig. 1B: 40 x Giemsa.

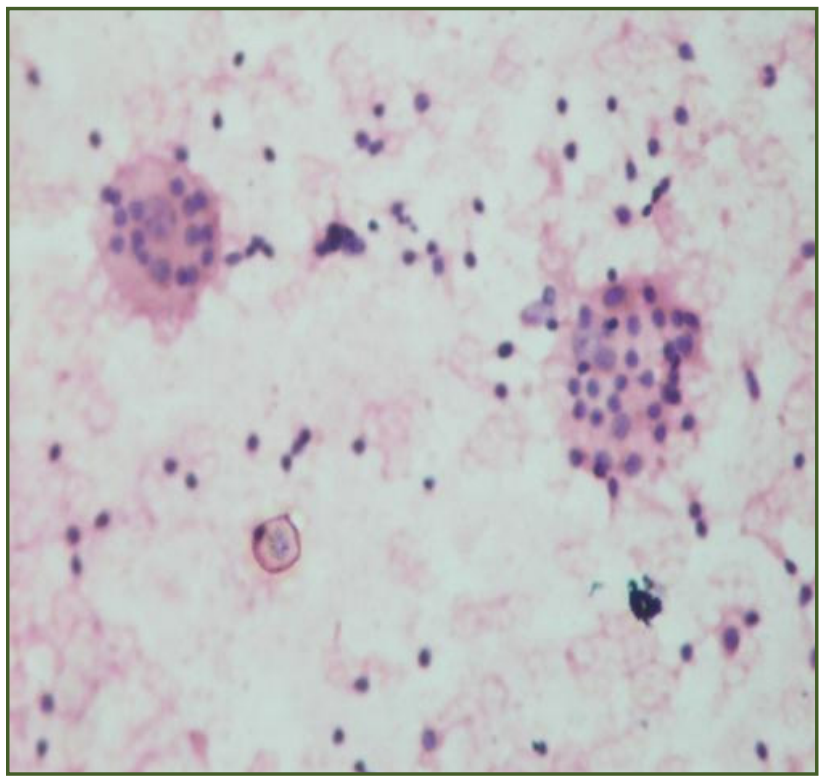

Fig. 3, 40 x Papanicolaou.

male preponderance ${ }^{(3)}$. Rosai - Dorfman Disease is a rare disorder of unknown etiology characterized frequently by spontaneous remission. ${ }^{(4)}$ Theories implicating that an aberrant exaggerated immune response to an infectious agent causes proliferation of histiocytes. The presence of human herpes virus 6 was demonstrated by in-situ hybridization. ${ }^{[3]}$ Relationship with klebsiella, Epstein-Barr virus, Brucella, or Cytomegalovirus were also suggested. $[3,5]$ It primarily involves lymph nodes but extra nodal involvement is also seen. Other sites of involvement are skin, upper respiratory tract, head and neck, eyes and 
occular adnexa, subcutaneous tissue, salivary glands, genitourinary tract, thyroid, breast, kidney, heart etc. It was first described by Destombes in 1965. ${ }^{[6]}$ Later Juan Rosai and Ronald F Dorfman in 1969 recognized this disease as a separate clinicopathologic entity and coined the term sinus histiocytosis with massive lymphadenopathy. ${ }^{[7]}$ It is a histiocytic disorder characterised by sinus enlargement with presence of histiocytes showing emperipolesis within histiocytes. ${ }^{[8,9,10]}$ Histiocytes do not show any groove or twisted nuclei. Histiocytes show positive immunostaining for S-100 protein and CD 68 antigen. ${ }^{[3]}$ It is a self limiting condition usually require no specific treatment. Although histological findings are well documented, there have been very few reports on FNAC. ${ }^{[11]}$ Deshpande et al in FNAC of 4 cases showed similar morphology with emperipolesis. ${ }^{[1]}$

\section{Conclusion}

Here we describe 5 cases of Rosai - Dorfman Disease with enlarged cervical lymph nodes . Hence Rosai -Dorfman Disease should be included as a differential diagnosis in all patients presenting with enlarged lymph nodes.

\section{Reference}

1. Juskevicius R, and Finlay JL. Rosai-Dorfman disease of parotid gland, cytologic and histopathologic findings with immunohistochemical correlation. Arch Pathol Lab Med 2001; 125: 1348-1350.

2. Lauwer GY, Perez-Atayde A, Dorfman RF, et al. The digestive system manifestations of Rosai- Dorfman disease (sinus histiocytosis with massive lymphadenopathy): review of 11 cases. Hum Pathol 2000; 31:380-385.
3. Kumar B, Karki S, Paudyal P. Diagnosis of sinus histiocytosis with massive lymphadenopathy ( Rosai- Dorfman disease) by fine needle aspiration cytology. Diagn Cytopathol 2008; $36: 691-5$

4. Jinyung Ju, Yong Soon Kwon, Kae Jung Jo et al. Sinus Histiocytosis with massive lymphadenopathy; A Case Report with Pleural Effusion and Cervical Lymphadenopathy. J Korean Med Sci 2009; 24:760-762.

5. Lampert F, Lennert K. Sinus Histiocytosis with massive lymphadenopathy: Fifteen new cases. Cancer 1976; 37:783-9.

6. Detombes P. Adenitis with lipid excess in children or young adults seen in Antilles and in Mali( 4 cases). Bull Soc Pathol ExotFiliales 1965; 58: 1169-75.

7. Rosai J, Dorfman RF. Sinus Histiocytosis with massive lymphadenopathy. Arch Pathol 1969;87:63-7.

8. Sujata G. Multifocal, Extranodal Sinus Histiocytosis With Massive Lymphadenopathy. An Overview. Arch Pathol Lab Med 2007;131: 1117-1121.

9. Das DK, Gulati A, Bhatt NC, Sethi GR. Sinus Histiocytosis with massive lymphadenopathy (Rosai- Dorfman disease): report of two cases with fine needle aspiration cytology. Diagn Cyto Pathol 2001;24:42-45.

10. Kushwaha R, Ahluwalia C, Sipayya K. Diagnosis of sinus histiocytosis with massive lymphadenopathy (RosaiDorfman disease) by fine needle aspiration cytology. Journal of Cytology 2009;26:83-85.

11. Deshpande AH, Nayak S, Munshi MM. Cytology of sinus histiocytosis with massive lymphadenopathy (RosaiDorfman disease). Diagn Cyto Pathol 2000;22:181-5. 